Review Article

\title{
High-Flow Nasal Cannula in Hypercapnic Respiratory Failure: A Systematic Review and Meta-Analysis
}

Yongkang Huang $\mathbb{D}$, Wei Lei, Wenyu Zhang, and Jian-an Huang $\mathbb{D}$

The First Affiliated Hospital of Soochow University, Suzhou, China

Correspondence should be addressed to Jian-an Huang; huang_jian_an@163.com

Received 28 May 2020; Revised 24 September 2020; Accepted 10 October 2020; Published 30 October 2020

Academic Editor: Rocco Trisolini

Copyright (c) 2020 Yongkang Huang et al. This is an open access article distributed under the Creative Commons Attribution License, which permits unrestricted use, distribution, and reproduction in any medium, provided the original work is properly cited.

Background. Although the efficacy and safety of high-flow nasal cannula (HFNC) in hypoxemic respiratory failure are widely recognized, it is yet unclear whether HFNC can effectively reduce the intubation rate and mortality in hypercapnic respiratory failure. We performed a systematic review and meta-analysis to assess the safety and efficiency of HFNC in these patients. Methods. A systematic search of PubMed, Embase, and Cochrane Library (CENTRAL) was carried out. Two reviewers independently screened all references according to the inclusion criteria. We used the Cochrane risk-of-bias tool and the Newcastle-Ottawa Quality Assessment Scale to assess the quality of randomized controlled trials (RCTs) and cohort studies, respectively. Data from eligible trials were extracted for the meta-analysis. Results. Eight studies with a total of 621 participants were included (six RCTs and two cohort studies). Our analysis showed that HFNC is noninferior to noninvasive ventilation (NIV) with respect to intubation rate in both $\mathrm{RCTs}(\mathrm{OR}=0.92,95 \% \mathrm{CI}: 0.45-1.88)$ and cohort studies $(\mathrm{OR}=0.94,95 \% \mathrm{CI}: 0.55-1.62)$. Similarly, the analysis of cohort studies showed no difference in reducing mortality rates (OR $=0.96,95 \%$ CI: $0.42-2.20)$. Based on RCTs, NIV seemed more effective in reducing mortality ( $\mathrm{OR}=1.33,95 \% \mathrm{CI}$ : 0.68-2.60), but the intertreatment difference was not statistically significant. Furthermore, no significant differences were found between HFNC and NIV relating to change of blood gas analysis or respiratory rate $(\mathrm{MD}=-0.75,95 \% \mathrm{CI}$ : -2.6 to 1.09$)$. Likewise, no significant intergroup differences were found with regard to intensive care unit stay $(\mathrm{SMD}=-0.07,95 \% \mathrm{CI}: 0.26$ to 0.11 ). Due to a physiological friendly interface and variation, HFNC showed a significant advantage over NIV in patients' comfort and complication of therapy. Conclusion. Despite the limitations noted, HFNC may be an effective and safe alternative to prevent endotracheal intubation and mortality when NIV is unsuitable in mild-to-moderate hypercapnia. Further high-quality studies are needed to validate these findings.

\section{Introduction}

Respiratory failure, which can occur due to several different diseases and conditions, is a common syndrome occurring in the intensive care unit (ICU) [1]. Endotracheal intubation is usually performed only when the patient is deteriorating despite optimal drug and common oxygen therapy, and it often results in extra medical expenses, longer hospital stay, and even higher mortality $[2,3]$. Thus, it is crucial to protect patients from acute respiratory failure and avoid, as far as possible, invasive mechanical ventilation.

Noninvasive ventilation (NIV) is recommended by guidelines to avoid intubation and improve outcomes [4]. However, many patients who need respiratory support may be excluded by the technicians for comorbidities such as emphysema and oversecretion of sputum $[5,6]$. Besides the contraindications, higher expenditure and numerous potential adverse events are presented during NIV, such as skin damage, eye irritation, interface intolerance, diet, and sputum retention, which cause discomfort and may lead to the termination of NIV to some extent [7].

High-flow nasal cannula (HFNC) is a simple system composed of an air-oxygen blender, active heated humidifier, single heated circuit, and nasal cannula and can deliver high-rate humidified oxygen (up to $60 \mathrm{~L} / \mathrm{min}$ ) through a nasal cannula. It has been deemed an effective and less costly alternative among children to alleviate respiratory distress and prevent extubation failure $[8,9]$. In recent years, HFNC 
has become increasingly popular in the treatment of respiratory failure in adults [10]. HFNC is reportedly superior to conventional oxygen therapy and can be as effective as NIV in patients with acute hypoxemic respiratory failure [11]. However, it is still unclear whether HFNC is an effective tool to reduce the intubation rate and mortality in patients suffering from hypercapnic respiratory failure.

\section{Methods}

This systematic review and meta-analysis was registered at PROSPERO (http://www.crd.york.ac.uk/prospero; CRD: 42020173744) and designed as per the Cochrane Handbook for Systematic Reviews of Interventions [12] and reported according to the PRISMA guidelines.

2.1. Literature Searching Strategy. We performed a comprehensive search of electronic databases including PubMed, Embase, and Cochrane Central Register of Controlled Trials (CENTRAL) up to May 2020, using the keywords and their synonyms, and the search was updated on September 12, 2020. Terms were related to the intervention and modified according to each database's index term, such as Medical Subject Heading (MeSH) and Emtree. No language restrictions or publication year were applied when searching PubMed and CENTRAL, while it was limited to clinical studies on humans on Embase. Relevant citations from the references listed in each identified study were also taken into consideration for eligibility. Detailed search terms are shown in Appendix 1 (Supplementary Materials (available here)).

2.2. Inclusion and Exclusion Criteria. Studies in our review had to meet all of the following criteria:

(1) Type of participants: participants must be adults (age $>16$ years) with acute hypercapnic respiratory failure $\left(\mathrm{PaCO}_{2}>45 \mathrm{mmHg}\right)$

(2) Type of intervention and comparator: comparing HFNC with NIV

(3) Type of studies: a randomized controlled trial (RCT) or a cohort study

(4) Containing any one of the following outcomes: intubation rate; mortality; blood gas analysis (arterial partial pressure of oxygen $\left(\mathrm{PaO}_{2}\right)$, arterial partial pressure of carbon dioxide $\left(\mathrm{PaCO}_{2}\right)$, and $\left.\mathrm{pH}\right)$; respiratory rate, patient comfort; and complication of the therapy

Exclusion criteria:

(1) Studies with the same data or overlapping data by the same authors

(2) Studies without any one of the predetermined outcomes

2.3. Quality Assessment. The quality of all selected studies was assessed independently by two reviewers (HYK and ZWY). RCTs were evaluated according to the Cochrane risk- of-bias tool which includes the following items: random sequence generation, allocation concealment, blinding of participants and personnel, blinding of outcome assessment, incomplete outcome data, selective reporting, and other biases. On the contrary, a cohort study was graded according to the Newcastle-Ottawa Quality Assessment Scale [13] with regard to selection, comparability, and outcome.

2.4. Data Extraction. Two researchers (HYK and ZWY) independently extracted the following data from each study: characters of the study (first author, publication year, country, number of participants, case source, cause of hypercapnic respiratory failure, and major inclusion criteria); characters of the participants (demographic variation and basic blood gas analysis); and the primary and secondary outcomes. Any disagreements between the two authors were resolved by consensus or cross-checking with a third author (LW). Additional information was collected through communication with the principal investigator by email if necessary.

2.5. Data Analysis. Statistical analysis was performed by an independent researcher adept in statistics using Cochrane systematic review software Review Manager (RevMan; version 5.4.0; The Nordic Cochrane Centre, The Cochrane Collaboration, Copenhagen, 2014). Continuous variables were reported as mean and standard derivation (SD), while dichotomous variables were shown as frequency or proportion. The results were displayed in forest plots. An initial test for clinical, methodological, and statistical heterogeneities was conducted, and we used the chi-square test with $P<0.1$ and $I^{2}>50 \%$ to indicate statistical significance. Random-effect model was applied in the presence of statistical heterogeneity; otherwise, the fixed-effect model was chosen. For continuous data, we calculated the mean difference $(\mathrm{MD})$ or standard mean difference (MD) and $95 \%$ confidence interval (CI), and for dichotomous data, we calculated the odds ratio (OR) and 95\% CI.

\section{Results}

3.1. Study Selection and Characteristics. In all, 595 citations were retrieved through literature search. We excluded 150 duplicates identified by the title and authors and omitted 423 studies that did not fulfill the inclusion criteria. We tried to obtain the full text of the remaining 22 searches. Finally, eight studies, comprising six parallel RCTs [14-19] and two cohort studies [20, 21], involving 621 participants were enrolled in the analysis. The flowchart of the study is shown in Figure 1.

Tan et al. conducted their study in two large tertiary care hospitals, while the remaining studies included were all carried out in a single center. Seven studies were performed in Asia and one in Greece. Most patients were admitted to the ICU or respiratory ICU. Three of six RCTs recruited only extubated patients, while patients with acute-exacerbation chronic obstructive pulmonary disease (AECOPD) were the main cause of hypercapnic respiratory failure in another two 

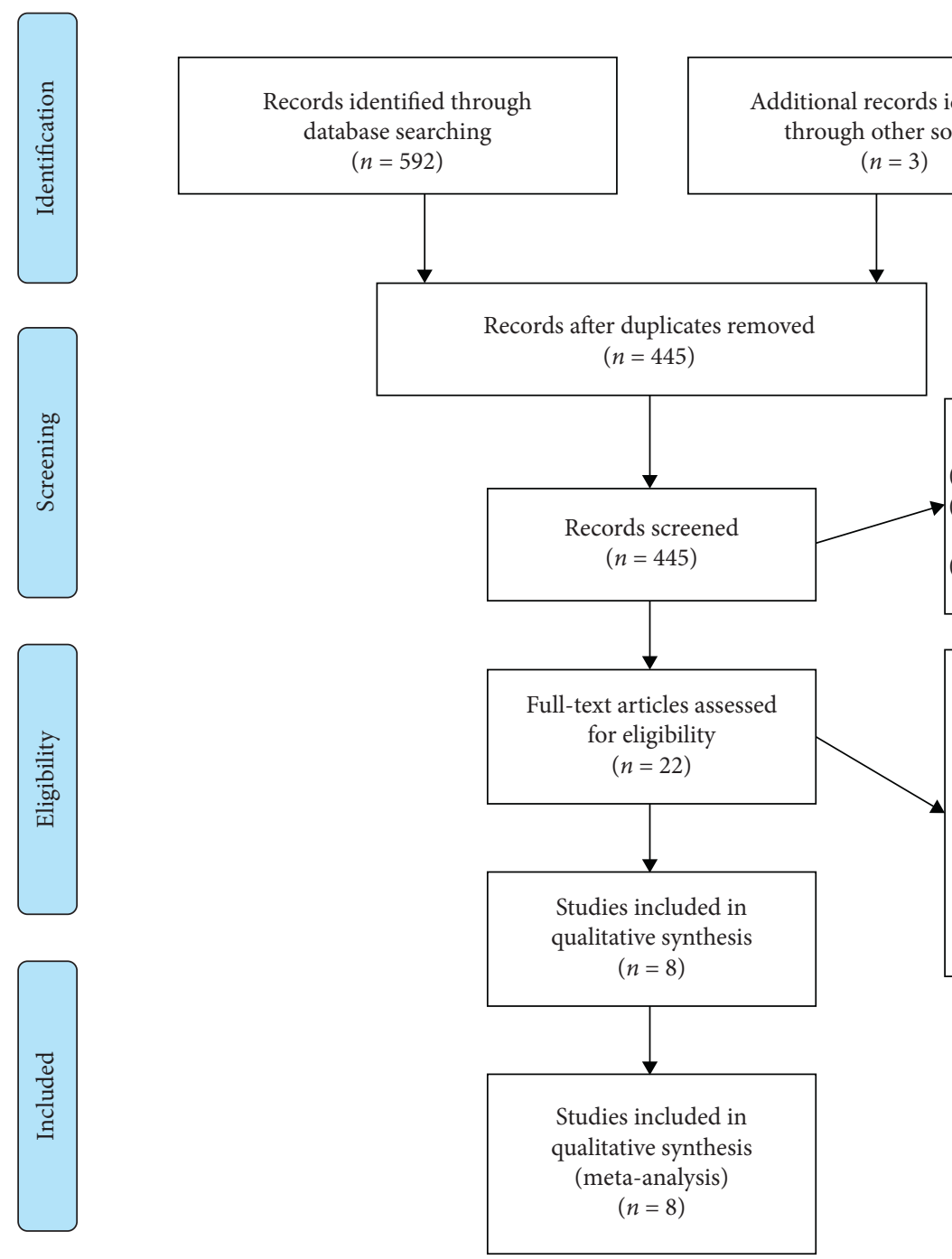

Records excluded $(n=423)$

(1) Not an RCT or a cohort study $(n=241)$

(2) Patients are not adults or did not suffer from $\mathrm{CO}_{2}$ retention $(n=58)$

(3) Did not compare HFNC with NIV $(n=124)$

Figure 1: Study flow.

RCTs and both cohort studies. One study did not mention the cause of admittance. Characteristics of the participants and studies are shown in Tables 1-3, respectively.

3.2. Risk of Bias within Studies. Three studies $[15,16,18]$ did not detail the method of their random sequence generation and allocation concealment, which may cause selection bias. Blinding of participants was not performed in all RCTs owing to different appearances of the devices. There was no bias in detection, attrition, and reporting. The quality assessment of each eligible trial is shown in Figure 2.

\subsection{Clinical Effectiveness}

3.3.1. Effect on Intubation Rate and Mortality. Both cohort studies and five RCTs that reported intubation and mortality were considered in our meta-analysis. The pooled data showed that HFNC was noninferior to NIV in preventing intubation or reintubation both in RCTs $(\mathrm{OR}=0.92,95 \% \mathrm{CI}$ : 0.45-1.88) and cohort studies $(\mathrm{OR}=0.94,95 \% \mathrm{CI}$ :
0.55-1.62). Similarly, the synthesis of cohort studies $(\mathrm{OR}=0.96,95 \% \mathrm{CI}: 0.42-2.20)$ in reducing mortality indicates no difference. NIV seems to be more effective in reducing mortality in RCTs (OR $=1.33,95 \% \mathrm{CI}$ : 0.68-2.60), but the between-treatment difference was not statistically significant. Forest plot of intubation and mortality is shown in Figure 3.

3.3.2. Effect on Blood Gas Analysis and Respiratory Rate. Of all eligible studies, seven reported at least one of the following blood gas analysis outcomes including $\mathrm{PaO}_{2}$, $\mathrm{PaCO}_{2}$, and $\mathrm{pH}$. The variables at $12 \mathrm{~h}$ or $24 \mathrm{~h}$ after initiation of therapy were collected and merged.

There was no difference between HFNC and NIV in oxygenation improvement $(\mathrm{MD}=0.35,95 \% \mathrm{CI}:-1.18$ to 1.89 in $\mathrm{PaO}_{2}$ and $\mathrm{MD}=-5.0595 \% \mathrm{CI}:-28.06$ to 17.97 in $\mathrm{PaO}_{2} / \mathrm{FiO}_{2}$ ); removing carbon dioxide $(\mathrm{MD}=-0.02,95 \% \mathrm{CI}$ : -2.62 to 2.59 for RCTs; $\mathrm{MD}=2.94,95 \% \mathrm{CI}$ : -0.20 to 6.07 for cohort studies); $\mathrm{pH}$ change ( $\mathrm{MD}=-0.01,95 \% \mathrm{CI}:-0.03$ to 0.01$)$; or alleviating respiratory distress $(\mathrm{MD}=-0.75,95 \% \mathrm{CI}-2.6$ to -1.09$)$. 


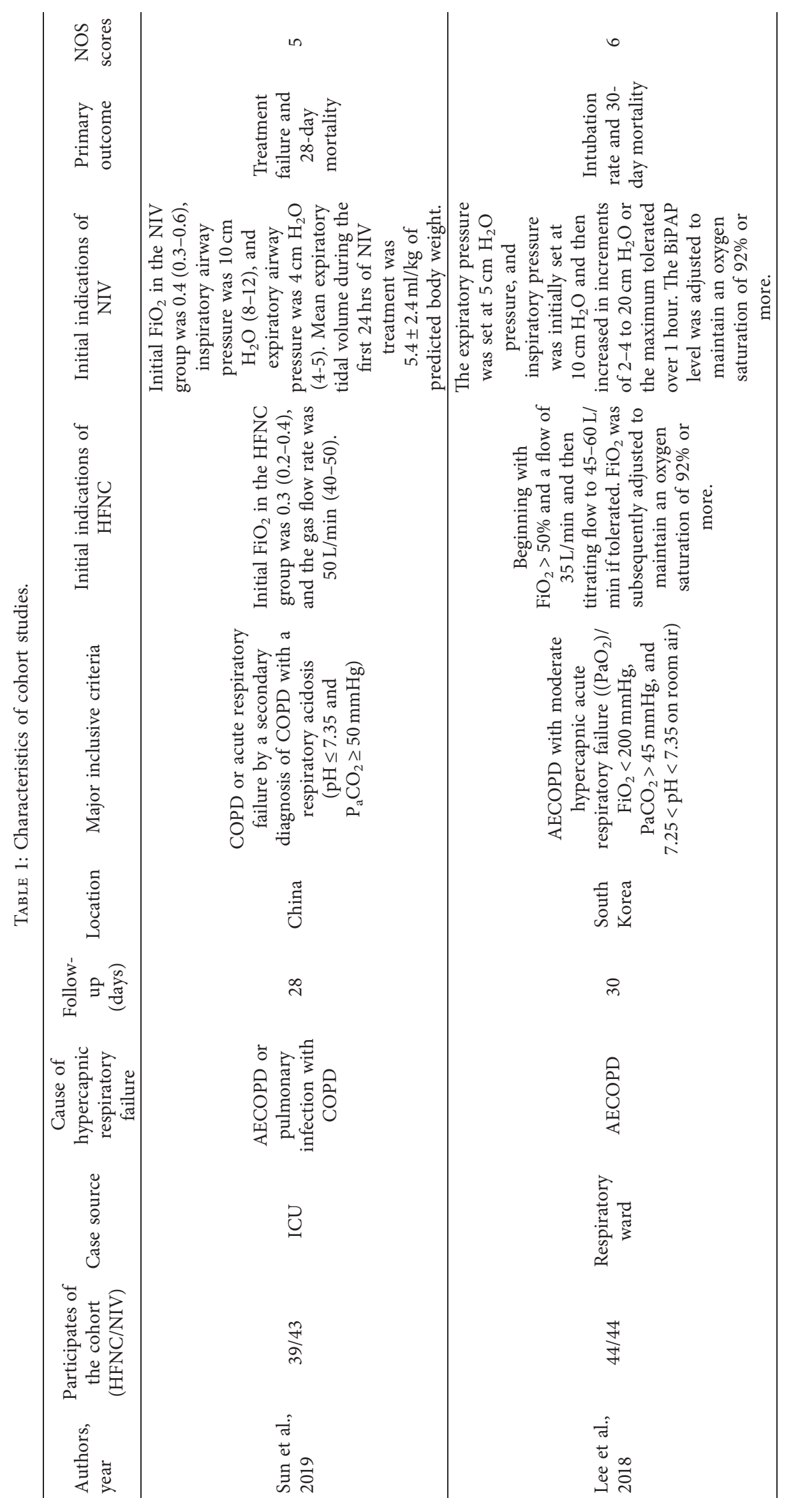




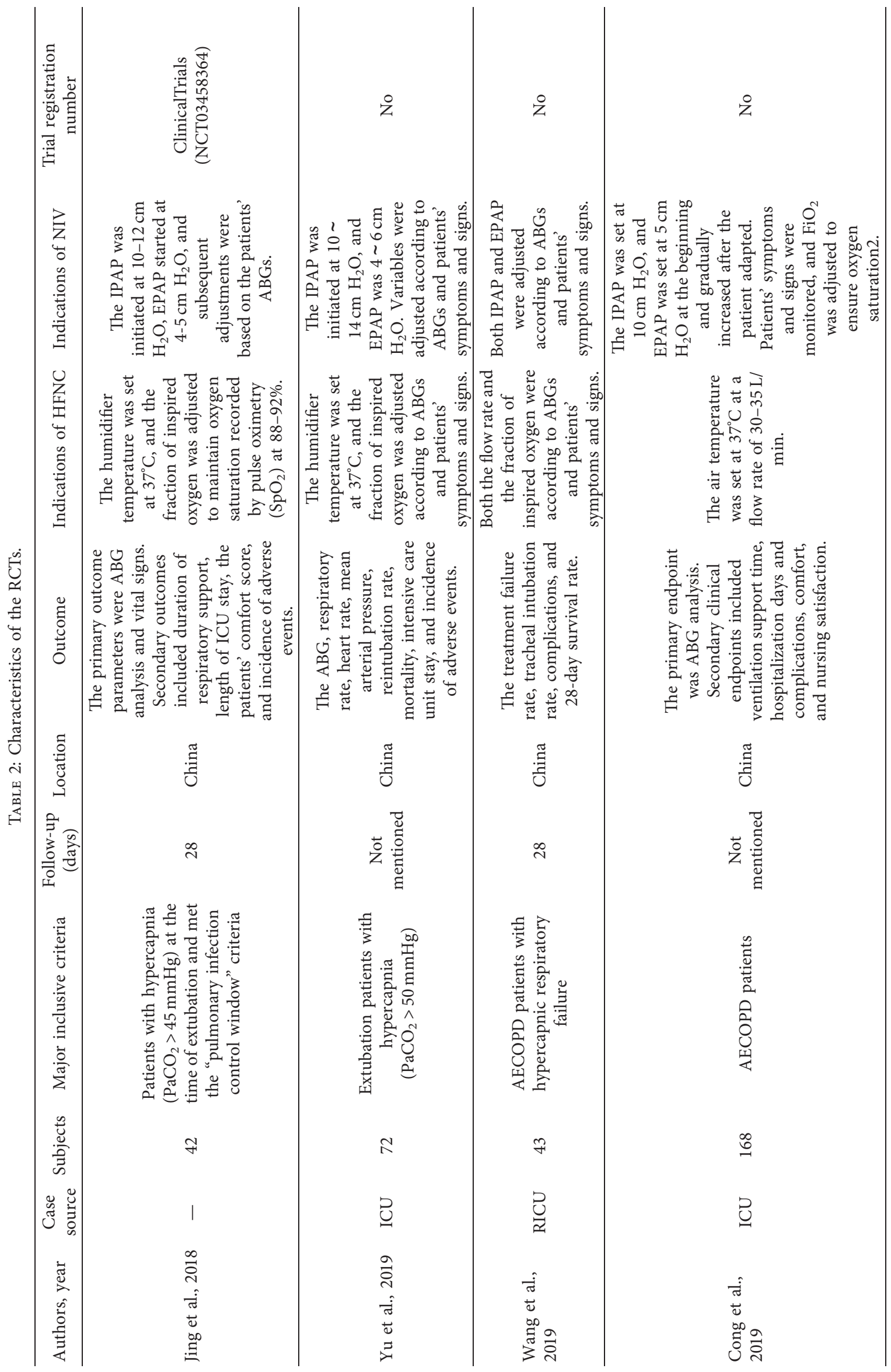




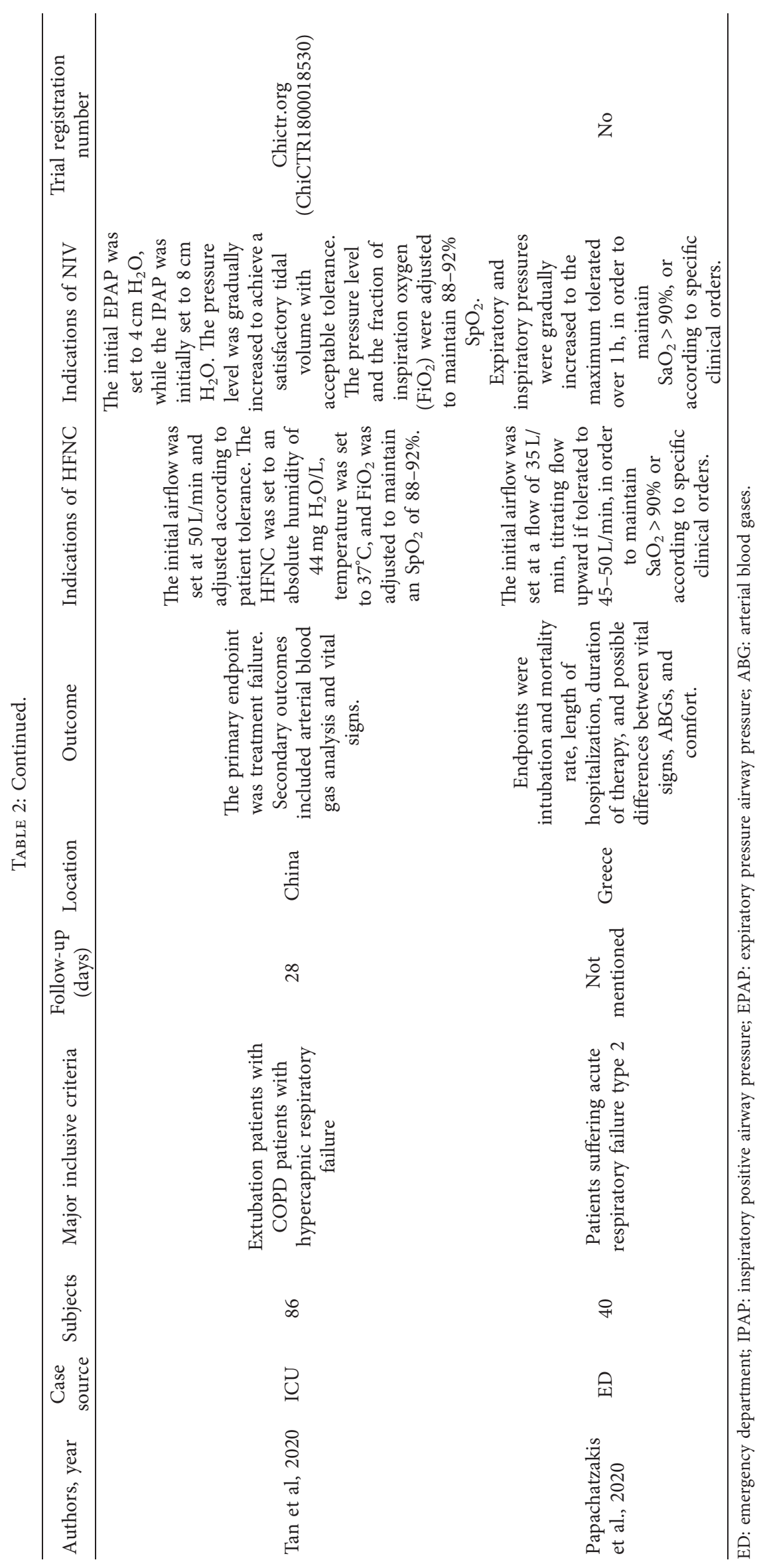




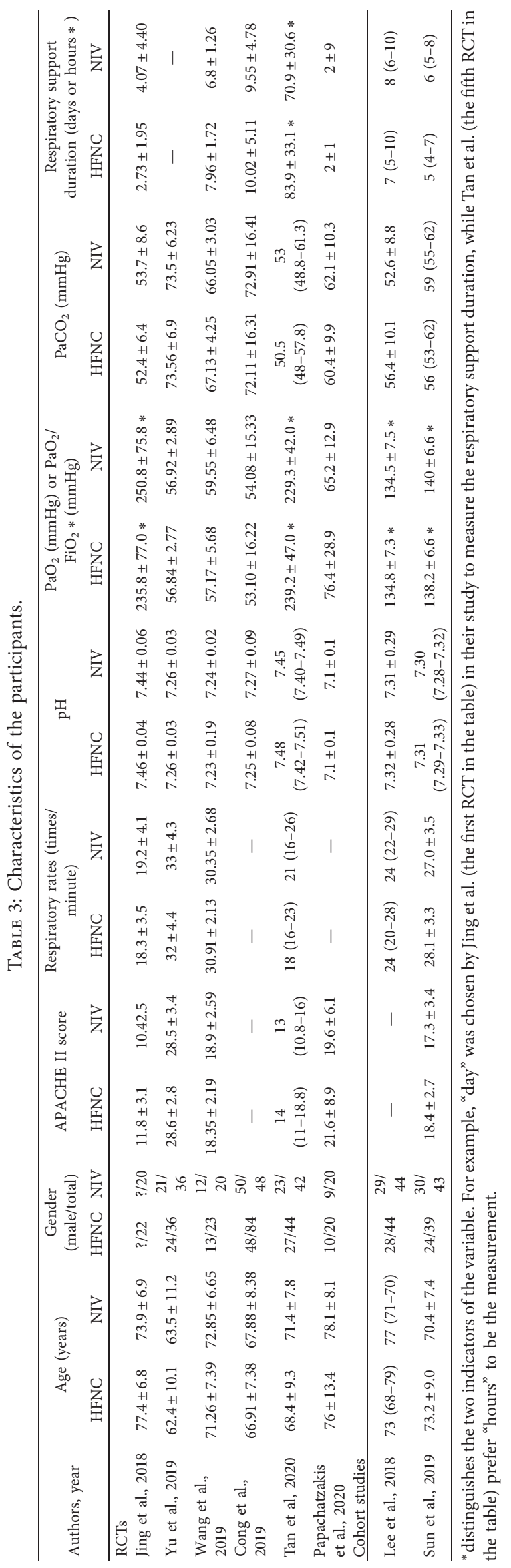




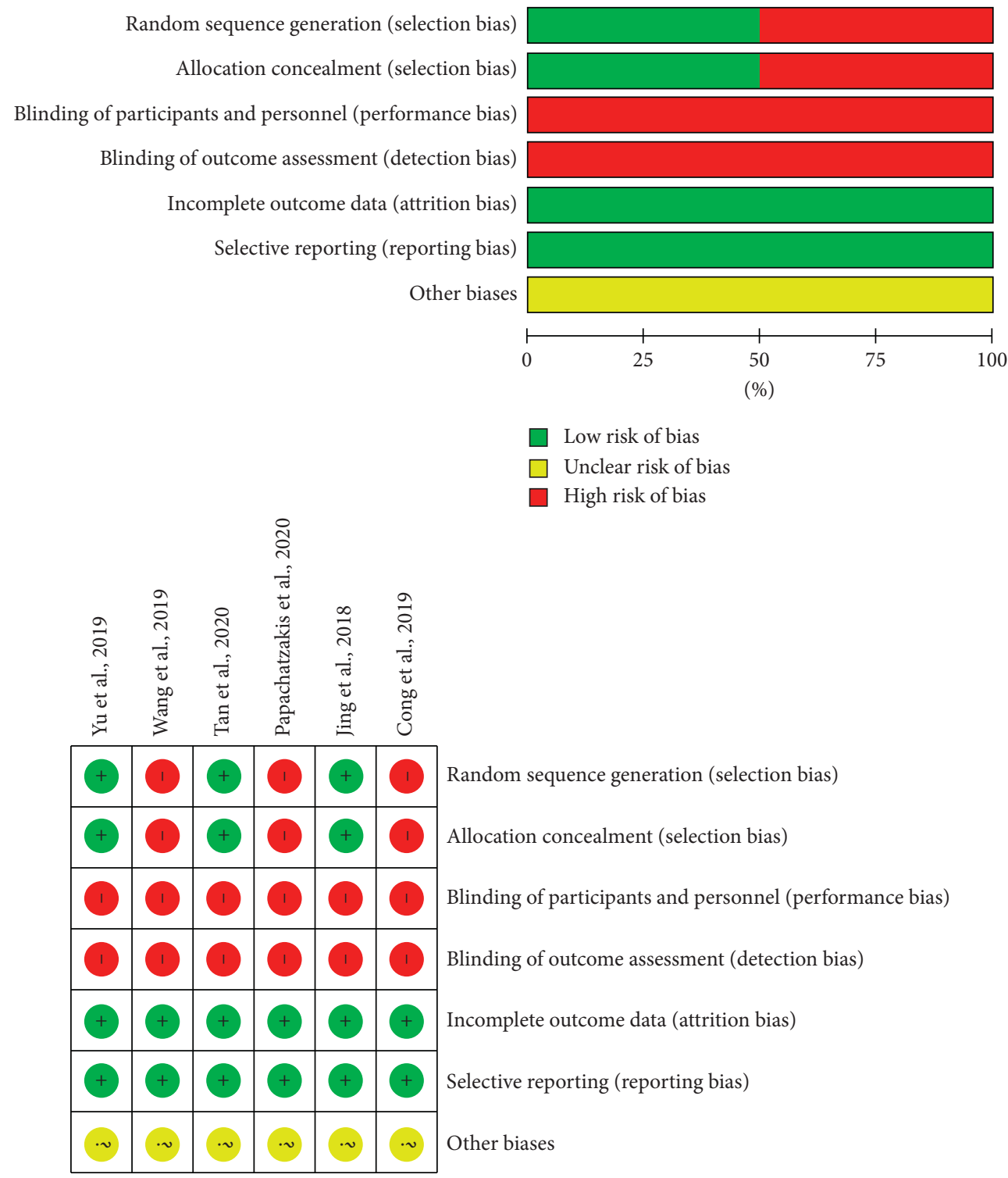

FIGURE 2: Quality assessment of each eligible trial.

Likewise, two cohort studies showed a similar tendency without a significant difference. Forest plots of blood gas analysis and respiratory rate are shown in Figure 4.

3.3.3. Effect on ICU Stay. All six RCTs reported the patients' stay in the ICU and were pooled into the analysis. The results suggested that both therapies were similar with respect to ICU stay (SMD $=-0.07,95 \% \mathrm{CI}:-0.26$ to 0.11$)$. Forest plot of ICU stay is shown in Figure 5.

\subsubsection{Patients' Comfort and Complications of Therapy.} Three studies $[14,15,19]$ that reported patients' comfort indicated a statistically significant effect in support of HFNC. Similarly, four studies $[16,17,19,20]$ that reported complications of therapy showed a significantly lower flatulence rate and incidence of nasal-facial breakdown rate in the HFNC group than in the NIV group (all $P<0.05$ ). Besides, fewer patients in the HFNC group needed less airway care intervention. The summary of patients' comfort and complication is shown in Table 4 .

3.3.5. Heterogeneity Analysis. Significant heterogeneity was tested in $\mathrm{PaCO}_{2}$ of the cohort studies $\left(I^{2}=87 \%, c^{2}=7.52\right.$, $P=0.006)$, but not among the RCTs $\left(I^{2}=30 \%, \chi^{2}=5.73\right.$, $P=0.22)$. There were good consistency and low heterogeneity among the other variables analyzed.

\section{Discussion}

The efficacy and safety of high-flow nasal cannula (HFNC) in patients with hypercapnic respiratory failure have been debatable in recent years. Pisani et al. [22] reported that COPD patients recovering from an acute exacerbation and with persistent hypercapnia showed a statistically significant response in terms of $\mathrm{PaCO}_{2}$ decrease. This was strengthened 


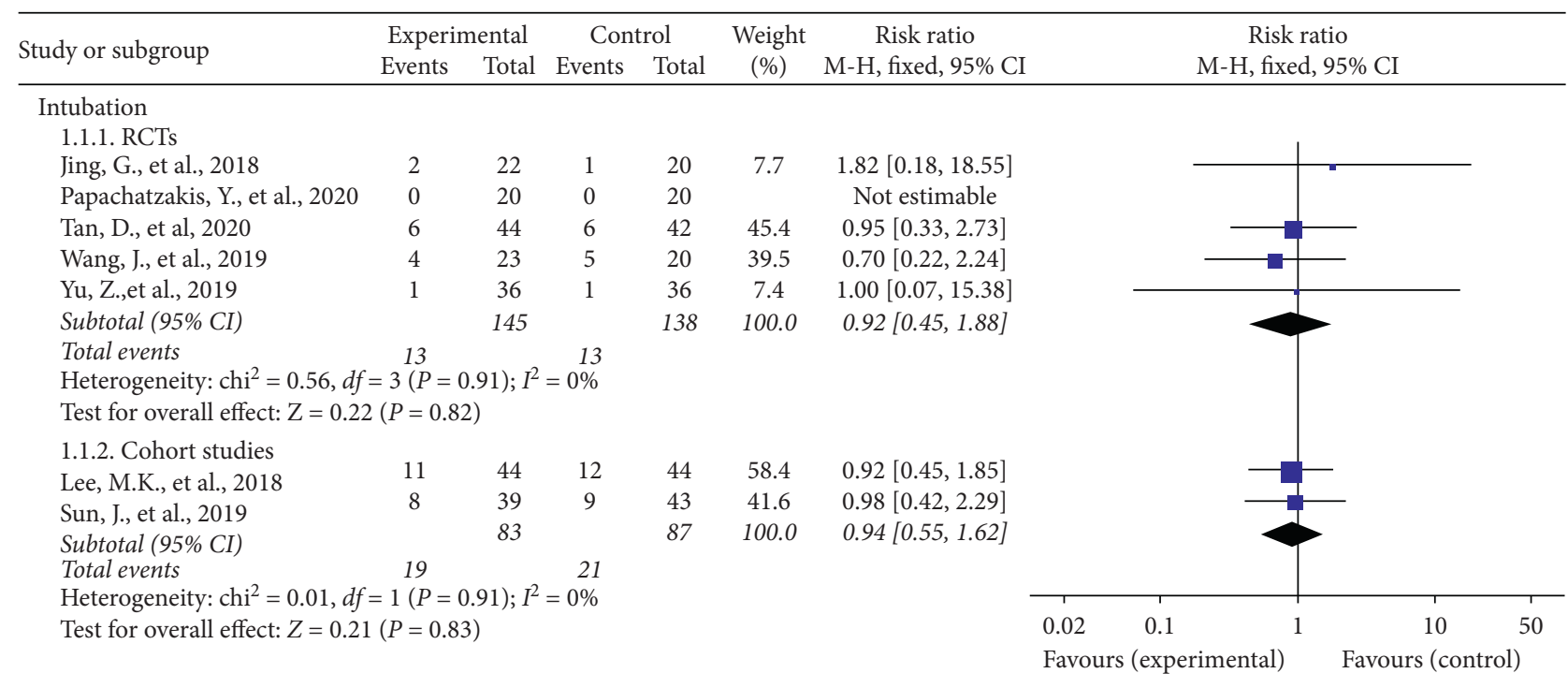

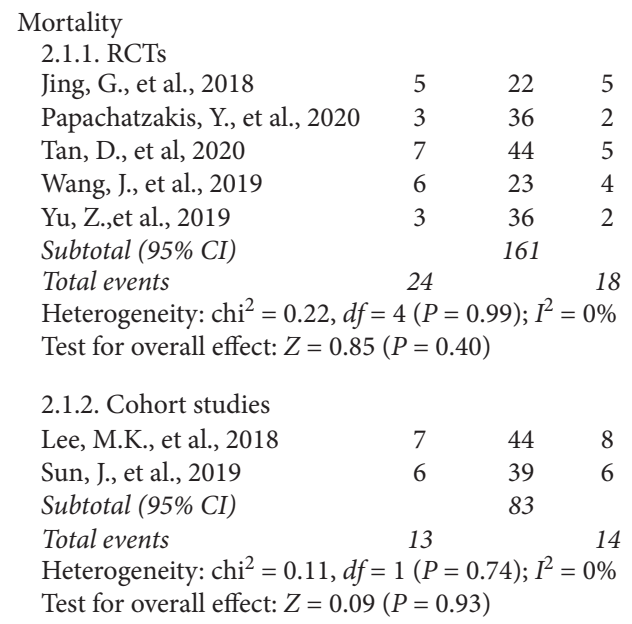

$\begin{array}{ccc}22 & 25.8 & 1.00[0.24,4.10] \\ 36 & 12.2 & 1.55[0.24,9.85] \\ 42 & 28.7 & 1.40[0.41,4.81] \\ 20 & 21.1 & 1.41[0.34,5.94] \\ 36 & 12.2 & 1.55[0.24,9.85] \\ 156 & 100.0 & 1.33[0.68,2.60]\end{array}$

$1.00[0.24,4.10]$

$1.55[0.24,9.85]$

$1.40[0.41,4.81]$

$1.55[0.24,9.85]$

$1.33[0.68,2.60]$

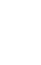




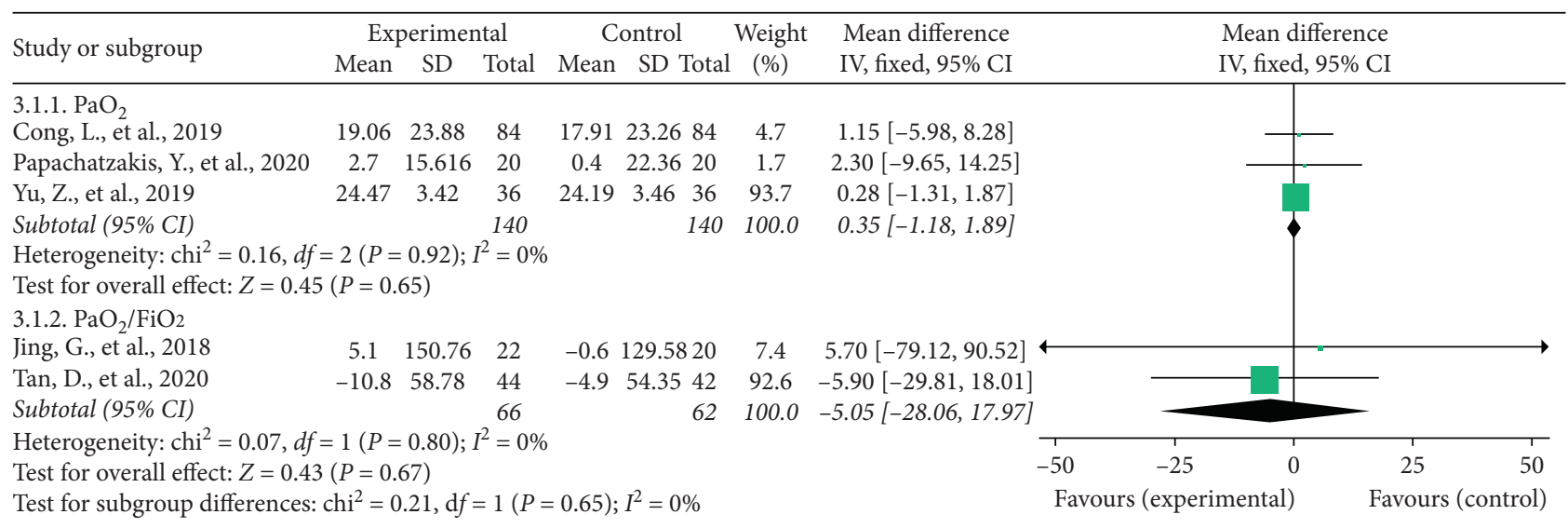

$\begin{array}{lcccccccc}\text { 3.2.1. PaCO } & \text { RCTs } \\ \text { Cong, L., et al., 2019 } & -8.94 & 22.79 & 84 & -9.85 & 22.89 & 84 & 14.2 & 0.91[-6.00,7.82] \\ \text { Jing, G., et al., 2018 } & 2.3 & 7.94 & 22 & 5.2 & 15.34 & 20 & 12.1 & -2.90[-10.40,4.60] \\ \text { Papachatzakis, Y., et al., 2020 } & -8.8 & 13.79 & 20 & -5.3 & 14.15 & 20 & 9.1 & -3.50[-12.16,5.16] \\ \text { Tan, D., et al., 2020 } & 3.5 & 9.86 & 44 & -0.5 & 11.12 & 42 & 34.3 & 4.00[-0.45,8.45] \\ \text { Yu, Z., et al., 2019 } & -16.53 & 10.91 & 36 & -13.72 & 9.52 & 36 & 30.3 & -2.81[-7.54,1.92] \\ \text { Subtotal (95\% CI) } & & & 206 & & & 202 & 100.0 & -0.02[-2.62,2.59]\end{array}$

Heterogeneity: chi $^{2}=5.73, d f=4(P=0.22) ; I^{2}=30 \%$

Test for overall effect: $Z=0.01(P=0.99)$

3.2.2. $\mathrm{PaCO}_{2}$ Cohort studies

$\begin{array}{lcccccccc}\text { Lee, M.K., et al., } 2018 & -9.4 & 18.92 & 44 & -3 & 16.28 & 44 & 18.1 & -6.40[-13.78,0.98] \\ \text { Sun, J., et al., 2019 } & -5 & 8.93 & 39 & -10 & 6.82 & 43 & 81.9 & 5.00[1.53,8.47]\end{array}$

$\begin{array}{lrrrr}\text { Subtotal }(95 \% \mathrm{CI}) & 83 & 87 & 100.0 & 2.94[-0.20,6.07]\end{array}$

Heterogeneity: chi $^{2}=7.52, d f=1(P=0.006) ; I^{2}=87 \%$

Test for overall effect: $Z=1.84(P=0.07)$

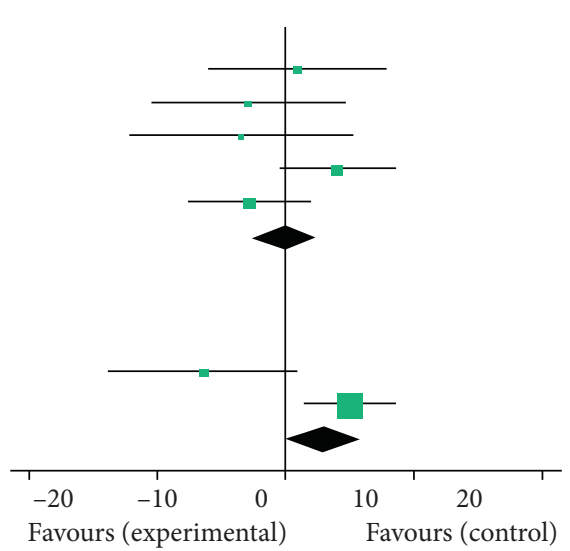

3.3.1.pH_RCTs

Cong, L., et al., 2019

Jing, G., et al., 2018

Papachatzakis, Y., et al., 2020

Tan, D., et al., 2020

Yu, Z.,et al., 2019

Subtotal (95\% CI)

$\begin{array}{ccccccc}0.09 & 0.12 & 84 & 0.09 & 0.108 & 84 & 36.5 \\ 0 & 0.058 & 22 & -0.02 & 0.078 & 20 & 24.8 \\ 0 & 0.141 & 20 & 0 & 0.141 & 20 & 5.7 \\ -0.04 & 0.086 & 44 & 0 & 0.086 & 42 & 32.9 \\ -0.91 & 1.031 & 36 & -0.94 & 1.031 & 36 & 0.2 \\ & & 206 & & & 202 & 100.0\end{array}$

Heterogeneity: chi $^{2}=4.95, d f=4(P=0.29) ; I^{2}=19 \%$

Test for overall effect: $Z=0.77(P=0.44)$

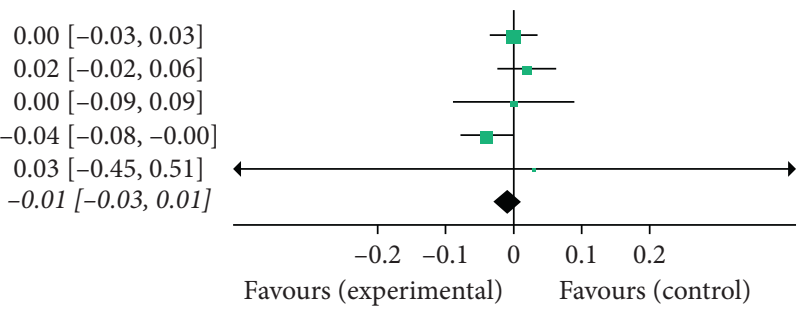

(a)

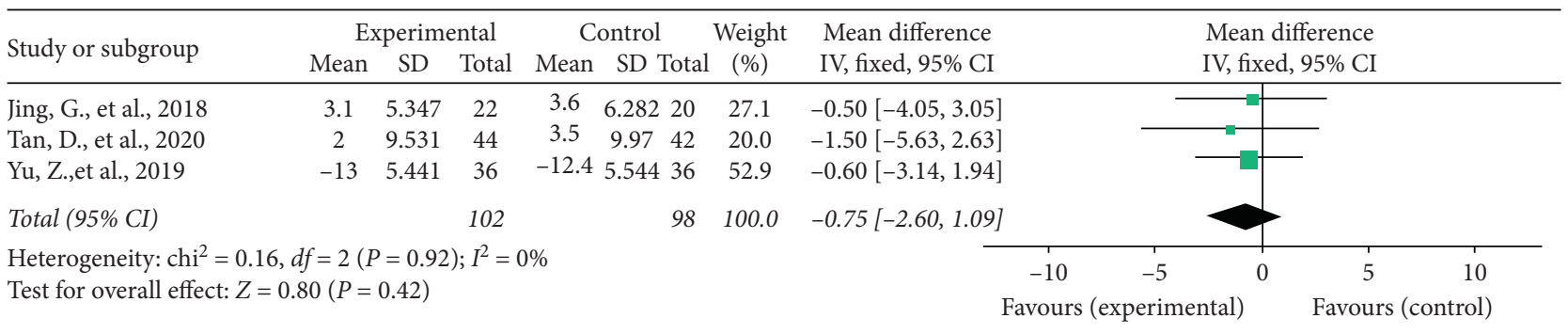

(b)

FIgURE 4: (a) Blood gas analysis. (b) Respiratory rate.

respiratory failure were limited. Second is the methodological issues of the included studies, for example, explicit randomization in partial studies, lack of blinding for all RCTs, and single-center design of most studies in Asia. These factors may lead to bias and weaken the strength of evidence. Besides, there was significant heterogeneity in the analysis of
$\mathrm{PaCO}_{2}$ in cohort studies $\left(I^{2}=87 \%, \chi^{2}=7.52, P=0.006\right)$, which was speculated to be caused by differences in the initial flow rate of HFNC and the overall severity of patients, deduced on the basis of different places from where patients were recruited. Thus, the quality of the included studies ranged from moderate to low. 


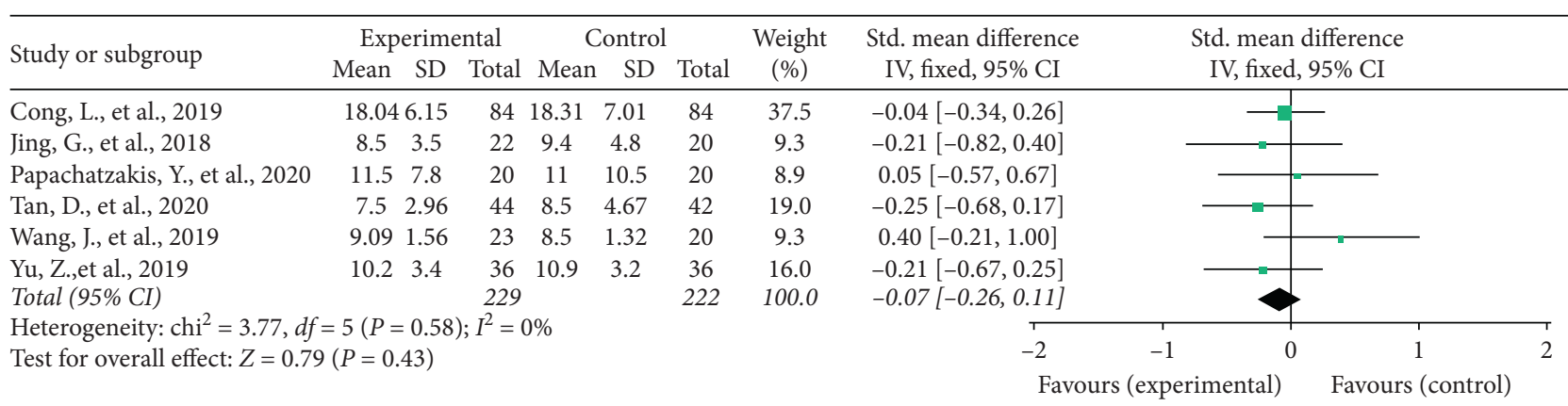

Figure 5: ICU stay.

TABLE 4: Summary of patients' comfort and complication.

\begin{tabular}{|c|c|c|c|c|}
\hline & $\begin{array}{c}\text { Nasofacial skin } \\
\text { breakdown }\end{array}$ & $\begin{array}{c}\text { Gastric and intestinal } \\
\text { flatulence }\end{array}$ & Comfort scores & Airway care interventions \\
\hline Sun et al., 2019 & $5.1 \%$ vs. $20.9 \%, P<0.05$ & - & - & 5 (4-7) vs. $8(7-10), P<0.001$ \\
\hline Jing et al., 2018 & - & - & $\begin{array}{c}3.55 \pm 2.01 \text { vs. } 5.15 \pm 2.28 \\
P=0.02\end{array}$ & $9.09 \%$ vs. $45 \%, P=0.03$ \\
\hline $\begin{array}{l}\text { Cong et al., } \\
2019\end{array}$ & - & - & $75 \%$ vs. $57 \%, P=0.008$ & - \\
\hline Yu et al., 2019 & - & $5.6 \%$ vs. $25 \%, P=0.022$ & - & - \\
\hline $\begin{array}{l}\text { Wang et al., } \\
2019\end{array}$ & $8.7 \%$ vs. $40 \%, P=0.028$ & $13.0 \%$ vs. $45.0 \%, P=0.039$ & - & - \\
\hline Tan et al., 2020 & 0 vs. $9.6 \%, P=0.027$ & - & 7 (6-8) vs. $5(4-7), P<0.001$ & $\begin{array}{c}6(4-7) \text { vs. } 7(5-9.3) \\
P=0.006\end{array}$ \\
\hline
\end{tabular}

\section{Conclusion}

Despite the limitations noted, HFNC may be an effective and safe alternative to prevent endotracheal intubation and mortality when NIV cannot be performed in mild-tomoderate cases of hypercapnia. Large and well-structured trials are needed to validate these findings.

\section{Data Availability}

The studies included can be found on PubMed except two RCTs, of which one was indexed in Embase (Yu ZH et al., Academic Journal of Second Military Medical University 2019, https://doi.org/10.16781/j.0258-879x.2019.09.0989), and the other (Wang et al., Chin J Mod Med 2019, https:// kns.cnki.net/kcms/detail/43.1225.R.20190613.1310.010.html) could be found on Chinese National Knowledge Infrastructure.

\section{Conflicts of Interest}

The authors declare no conflicts of interest.

\section{Acknowledgments}

This work was supported by grants from Science and Education of Public Health Project for Young Medical Talents of Jiangsu Province (no. QNRC2016747), Jiangsu Provincial Key Medical Discipline (no. ZDXKB2016007), the Gusu Youth Medical Talent (no. 3101030342000318), the Science and Technology Development Projects of Suzhou (no.
SYS2020008), the Introduction of Clinical Medicine Expert Team Projects of Suzhou (no. SZYJTD201801), and the Clinical Medicine Center of Suzhou (no. Szzx201502).

\section{Supplementary Materials}

This section includes Appendix 1 with detailed search terms. (Supplementary Materials)

\section{References}

[1] D. Cook, R. Brower, J. Cooper, L. Brochard, and J.-L Vincent, "Multicenter clinical research in adult critical care," Critical Care Medicine, vol. 30, no. 7, pp. 1636-1643, 2002.

[2] C. Roussos and A. Koutsoukou, "Respiratory failure," European Respiratory Journal, vol. 22, no. Supplement 47, pp. 3s-14s, 2003.

[3] A. Esteban, A. Anzueto, F. Frutos et al., "Characteristics and outcomes in adult patients receiving mechanical ventilation," Journal of the American Medical Association, vol. 287, pp. 345-355, 2002.

[4] B. Rochwerg, L. Brochard, M. W. Elliott et al., "Official ERS/ ATS clinical practice guidelines: noninvasive ventilation for acute respiratory failure," European Respiratory Journal, vol. 50, no. 2, p. 1602426, 2017.

[5] F. Vagnarelli, M. Marini, G. Caretta et al., "Noninvasive ventilation: general characteristics, indications, and review of the literature," Giornale italiano di cardiologia (Rome), vol. 18, pp. 496-504, 2017.

[6] G. Bello, G. De Pascale, and M. Antonelli, "Noninvasive ventilation," Clinics in Chest Medicine, vol. 37, pp. 711-721, 2016. 
[7] C. Crimi, A. Noto, P. Princi, A. Esquinas, and S. Nava, "A European survey of noninvasive ventilation practices," European Respiratory Journal, vol. 36, pp. 362-369, 2010.

[8] N. Fleeman, J. Mahon, V. Bates et al., "The clinical effectiveness and cost-effectiveness of heated humidified high-flow nasal cannula compared with usual care for preterm infants: a systematic review and economic evaluation," Health Technology Assessment, vol. 20, pp. 1-68, 2016.

[9] M. Nishimura, "High-flow nasal cannula oxygen therapy devices," Respiratory Care, vol. 64, pp. 735-742, 2019.

[10] M. S. Stefan, P. Eckert, B. Tiru et al., "High flow nasal oxygen therapy utilization: 7-year experience at a community teaching hospital," Hospital Practice (1995), vol. 46, pp. 73-76, 2018.

[11] Y. Ni, J. Luo, H. Yu et al., "Can high-flow nasal cannula reduce the rate of endotracheal intubation in adult patients with acute respiratory failure compared with conventional oxygen therapy and noninvasive positive pressure ventilation?" Chest, vol. 151, pp. 764-775, 2017.

[12] J. P. T. Higgins and S. Green, Cochrane Handbook for Systematic Reviews of Interventions, The Cochrane Collaboration, London, UK, 2008, http://www.cochrane-handbook.org.

[13] G. Wells, B. Shea, D. O'Connell et al., "The Newcastle-Ottawa Scale (NOS) for assessing the quality if nonrandomized studies in meta-analyses," 2000, http://www.ohri.ca/ programs/clinical_epidemiology/oxford.htm.

[14] G. Jing, J. Li, D. Hao et al., "Comparison of high flow nasal cannula with noninvasive ventilation in chronic obstructive pulmonary disease patients with hypercapnia in preventing post-extubation respiratory failure: a pilot randomized controlled trial," Research and Nursing Health, vol. 42, pp. 217225, 2019.

[15] L. Cong, L. Zhou, H. Liu et al., "Outcomes of high-flow nasal cannula versus non-invasive positive pressure ventilation for patients with acute exacerbations of chronic obstructive pulmonary disease," International Journal of Clinical and Experimental Medicine, vol. 12, pp. 10863-10867, 2019.

[16] J. J. Wang, H. Y. Jiang, and Q. Li, "Randomized controlled study of HFNC and NPPV in the treatment of AECOPD combined with type II respiratory failure," Chinese Journal of Integrative Medicine, pp. 1-15, 2019, https://kns.cnki.net/ $\mathrm{kcms} /$ detail/43.1225.R.20190613.1310.010.html.

[17] Z. H. Yu, R. Zhang, H. Huang et al., "Efficacy and safety of humidified high flow nasal cannula in chronic obstructive pulmonary disease complicated with type 2 respiratory failure patients after extubation: a randomized controlled trial," Academic Journal of Second Military Medical University, vol. 40, pp. 989-994, 2019.

[18] Y. Papachatzakis, P. T. Nikolaidis, S. Kontogiannis et al., "High-flow oxygen through nasal cannula vs. Non-invasive ventilation in hypercapnic respiratory failure: a randomized clinical trial," International Journal of Environmental Research and Public Health, vol. 17, pp. 1-8, 2020.

[19] D. Tan, J. H. Walline, B. Ling et al., "High-flow nasal cannula oxygen therapy versus non-invasive ventilation for chronic obstructive pulmonary disease patients after extubation: a multicenter, randomized controlled trial," Critical Care, vol. 24, p. 489, 2020.

[20] J. Sun, Y. Li, B. Ling et al., "High flow nasal cannula oxygen therapy versus non-invasive ventilation for chronic obstructive pulmonary disease with acute-moderate hypercapnic respiratory failure: an observational cohort study," International Journal of Chronic Obstructive Pulmonary Disease, vol. 14, pp. 1229-1237, 2019.
[21] M. K. Lee, J. Choi, B. Park et al., "High flow nasal cannula oxygen therapy in acute-moderate hypercapnic respiratory failure," Clinical Respiratory Journal, vol. 12, pp. 2046-2056, 2018.

[22] L. Pisani, S. Betti, C. Biglia et al., "Effects of high-flow nasal cannula in patients with persistent hypercapnia after an acute COPD exacerbation: a prospective pilot study," BioMed Central Pulmonary Medicine, vol. 20, p. 12, 2020.

[23] J. Bräunlich and H. Wirtz, "Nasal high-flow in acute hypercapnic exacerbation of COPD," International Journal of Chronic Obstructive Pulmonary Disease, vol. 13, pp. 38953897, 2018.

[24] A. Pandya, G. Criner, J. So et al., "Tolerance and safety of humidified high-flow nasal cannula oxygen therapy in patients hospitalized with an acute exacerbation of chronic obstructive pulmonary disease (COPD)," American Journal of Respiratory and Critical Care Medicine, vol. 199, 2019.

[25] S. Yang, G. Zhang, Z. Liu et al., "Effect of high-flow nasal cannula oxygen therapy on diaphragmatic function in patients with acute exacerbation of chronic obstructive pulmonary disease: a prospective randomized controlled trial," Zhonghua Wei Zhong Bing Ji Jiu Yi Xue, vol. 31, pp. 551-555, 2019.

[26] A. Attaway, J. A. Faress, and F. Jacono, "Safety and efficacy of oxygen delivery via high flow nasal cannula (HFNC) in patients with structural lung disease and chronic respiratory failur," American Journal of Respiratory and Critical Care, vol. 197, 2018.

[27] P. J. Biselli, J. P. Kirkness, L. Grote et al., "Nasal high-flow therapy reduces work of breathing compared with oxygen during sleep in COPD and smoking controls: a prospective observational study," Journal of Applied Physiology (1985), vol. 122, pp. 82-88, 2017.

[28] S. Mckinstry, J. Pilcher, G. Bardsley et al., "Nasal high flow therapy and $\mathrm{PtCO}_{2}$ in stable COPD: a randomized controlled cross-over trial," Respirology, vol. 23, no. 4, pp. 378-384, 2017.

[29] P. Biselli, K. Fricke, L. Grote et al., "Reductions in dead space ventilation with nasal high flow depend on physiological dead space volume: metabolic hood measurements during sleep in patients with COPD and controls," European Respiratory Journal, vol. 51, 2018.

[30] C. F. Adams, P. H. Geoghegan, C. J. Spence et al., "Modelling nasal high flow therapy effects on upper airway resistance and resistive work of breathing," Respiratory Physiology and Neurobiology, vol. 254, pp. 23-29, 2018.

[31] L. Pisani, L. Fasano, N. Corcione et al., "Change in pulmonary mechanics and the effect on breathing pattern of high flow oxygen therapy in stable hypercapnic COPD," Thorax, vol. 72, pp. 373-375, 2017.

[32] J. F. Fraser, A. J. Spooner, K. R. Dunster et al., "Nasal high flow oxygen therapy in patients with COPD reduces respiratory rate and tissue carbon dioxide while increasing tidal and endexpiratory lung volumes: a randomised crossover trial," Thorax, vol. 71, pp. 759-761, 2016.

[33] R. Di Mussi, S. Spadaro, T. Stripoli et al., "High-flow nasal cannula oxygen therapy decreases post-extubation neuroventilatory drive and work of breathing in patients with chronic obstructive pulmonary disease," Critical Care, vol. 22, p. 180, 2018.

[34] A. Corley, L. R. Caruana, A. G. Barnett et al., "Oxygen delivery through high-flow nasal cannulae increase end-expiratory lung volume and reduce respiratory rate in post-cardiac surgical patients," British Journal of Anaesthesia, vol. 107, pp. 998-1004, 2011. 
[35] N. Groves and A. Tobin, "High flow nasal oxygen generates positive airway pressure in adult volunteers," Australian Critical Care, vol. 20, pp. 126-131, 2007.

[36] J. Bräunlich, F. Mauersberger, and H. Wirtz, "Effectiveness of nasal high flow in hypercapnic COPD patients is flow and leakage dependent," BMC Pulmonary Medicine, vol. 18, p. 14, 2018. 